\title{
DISTRIBUTION AND ABUNDANCE OF THE CATTLE TAIL LOUSE, HAEMATOPINUS QUADRIPERTUSUS FAHR. (ANOPLURA, HAEMATOPINIDAE) IN PUERTO RICO
}

A sanitary-entomological survey of dairy farms was conducted throughout Puerto Rico during the period September 1969 through May 1970 during which the authors tabulated data concerning the abundance and distribution of lice attacking dairy cattle cn 60 farms.

The farms were selected at random from a list of Grade $A$ dairies of Puerto Rico, compiled by the Department of Agriculture. The selected farms represented a wide variety of environmental areas at Isabela, Hatillo, Arecibo, Barceloneta, Manatí, Dorado, Toa Baja, Carolina, and Río Grande on the north ceast; Luquillo, Fajardo, Humacao, and Ceiba on the east coast; Lajas, Sabana Grande, Peñuelas, Juana Díaz, Santa Isabel, Salinas and Guayama on the south coast; Cabo Rojo on the west coast; and Coamo, Aibonito, Cayey, Cidra, Aguas Buenas, Caguas, Gurabo and Ceiba on the east-central part of the Island.

Adults and eggs of a louse species were collected from the tails and eye lids of cattle on 59 of the 60 farms. This species was identified by Dr. K. C. Emerson, Collaborator, U. S. National Museum, as the cattle tail louse, Haematopinus quadripertusus Fahrenholz.

Slides of these have been deposited in the collections of the U.S. National Museum in Washington, D.C., the Department of Biology at Mayagüez, and the Department of Entomology of the Agricultural Experiment Station at Río Piedras.

Wolcott, in his "Insects of Puerto Rico", states "Dr. H. E. Ewing also identified for Dr. H. L. Volkenberg Haematopinus eurysternus Nitsch of which heavy infestations have been noted on the body or eyelids of cattle, and Haematopinus tuberculatus Burmeister which is very common in the switch of the tail of cattle in the south coast." Haematopinus tuberculatus is a common parasite of the water buffalo or carabao, thus a possibility that Volkenberg's original specimens were misidentified. Our specimens of lice from eyelids were $H$. quadripertusus, not $H$. eurysternus. This suggests either a second misidentification or perhaps both species occur in the island.

A light louse infestation generally is considered one to three lice per square inch of animal surface. ${ }^{2}$ Our data show that infestations generally were light and only in one case (at Arecibo) were infestations sufficiently numerous to cause sloughing of the epidermis and hair of the tail in two out of a herd of 80 cows.

${ }^{1}$ Wolcott, G. N., The insects of Puerto Rico, J. Agr. Univ. P.R. $82(1-4): 975$ pp., 1948.

${ }^{2}$ Survey Methods for Some Economic Insects, ARS-81-3, USDA, May 1969. (Compiled by ARs). 


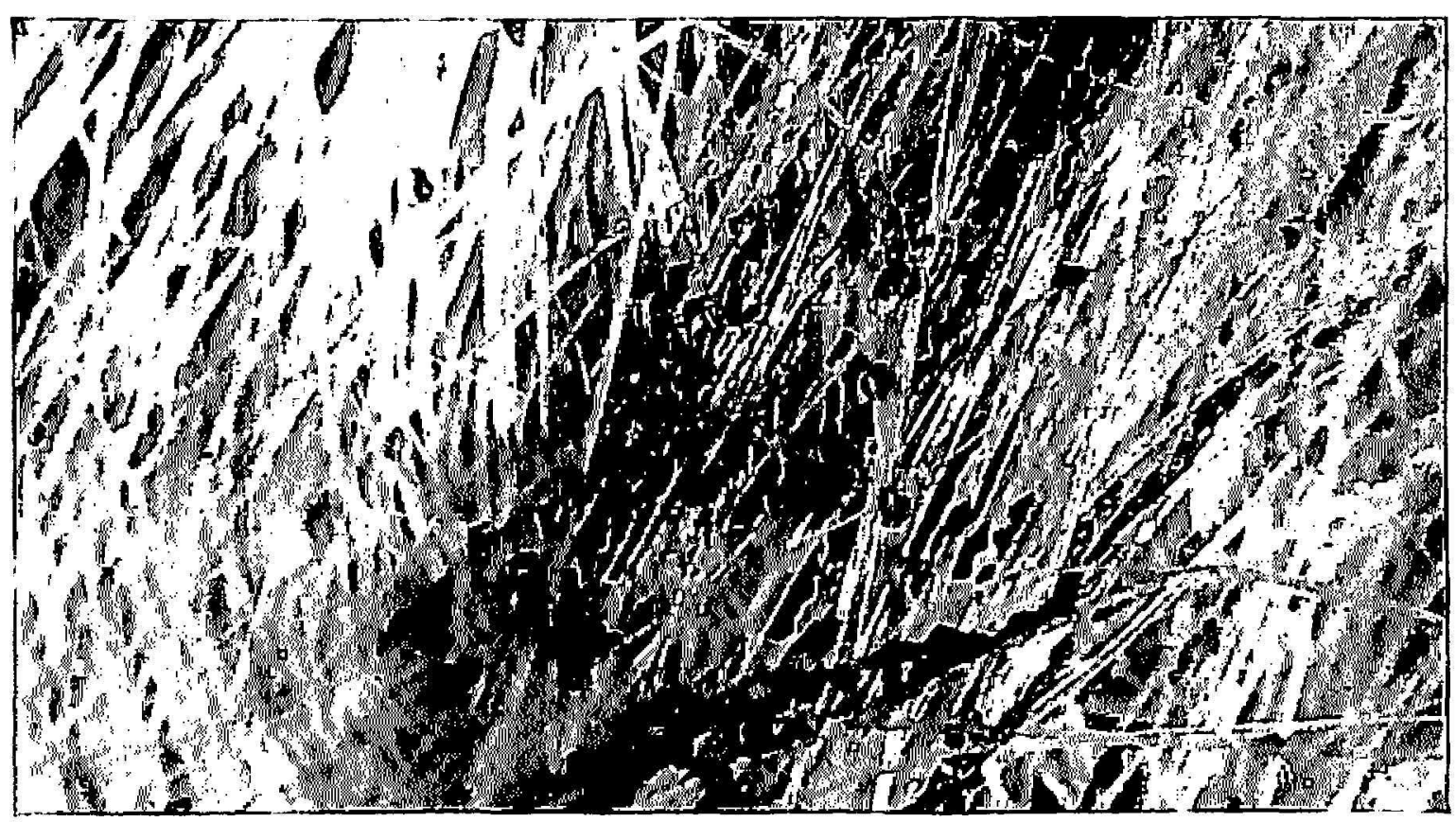

FIg. 1.-Eggs of the cattle tail louse (Haematopinus quadriperlusus) attached to hairs of the tail.

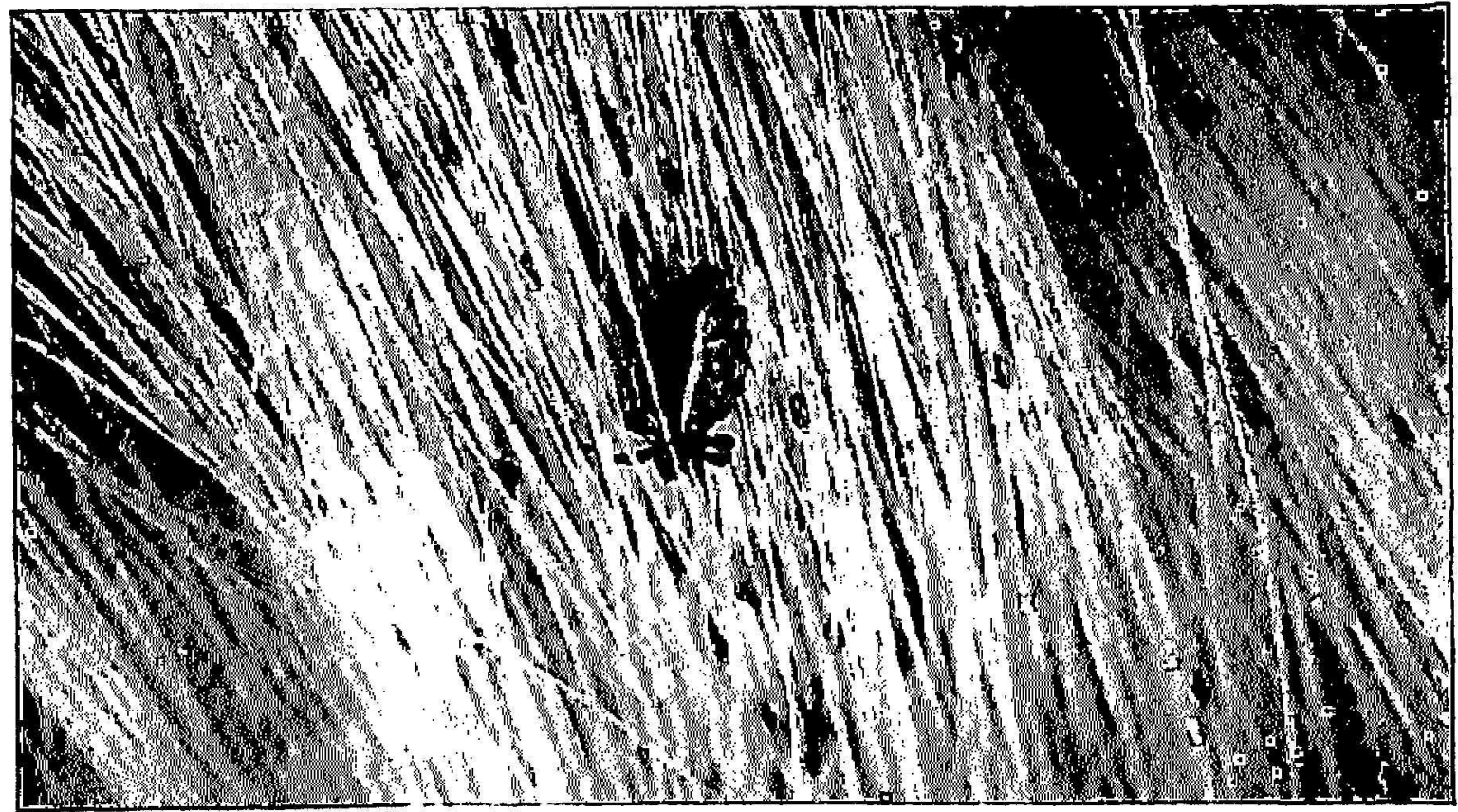

Fig. 2.-A feeding adult of the cattle tail louse.

Jenaro Maldonado Capriles

Department of Biology

Mayagriez Campus

Silverio Medina Gaud

Department of Entomology

Ayricultural Experiment Slation,

University of Puerto Rico

Rio Piedras, P.R. 